Bayer, Chugai, Corbus Pharmaceuticals, CSL Behring and Reata Pharmaceuticals. He was a member of the SENSCIS trial Steering Committee (Boehringer Ingelheim) DOI: 10.1136/annrheumdis-2020-eular.3993

\section{SAT0348 \\ CLINICAL SPECTRUM TIME COURSE OF ANTISYNTHETASE SYNDROME PATIENTS POSITIVE FOR ANTICENTROMERE ANTIBODIES}

G. Zanframundo ${ }^{1}$, G. Sambataro ${ }^{2}$, V. Codullo ${ }^{1}$, A. Biglia ${ }^{1}$, E. Bozzalla Cassione ${ }^{1}$, E. Bravi ${ }^{3}$, F. lannone ${ }^{4}$, M. Fornaro ${ }^{4}$, K. Triantafyllias ${ }^{5}$, A. Pesci ${ }^{6}$, P. Tomietto ${ }^{7}$, Ø. Molberg $^{8}$, S. Scarpato ${ }^{9}$, R. Voll ${ }^{10}$, M. Matucci-Cerinic ${ }^{11}$, M. A. González-Gay ${ }^{12}$, C. Montecucco ${ }^{1}$, L. Cavagna ${ }^{1}$ on behalf of on behalf of AENEAS Collaborative Group. ${ }^{1}$ University of Pavia, Rheumatology, Pavia, Italy; ${ }^{2}$ University of Catania, Pneumology and Rheumatology, Catania, Italy; ${ }^{3}$ Guglielmo da Saliceto Hospital, Rheumatology, Piacenza, Italy; ${ }^{4}$ University of Bari, Rheumatology, Bari, Italy; ${ }^{5}$ ACURA Center for Rheumatic Diseases, Rheumatology, Bad Kreuznach, Germany; ${ }^{6}$ University of Milano Bicocca, Pneumology, Milan, Italy; ${ }^{7}$ Cattinara Hospital, Rheumatology, Trieste, Italy; ${ }^{8}$ University of Oslo, Rheumatology, Oslo, Norway; ${ }^{9}$ Scarlato Hospital, Rheumatology, Scafati, Italy; ${ }^{10}$ University of Freiburg, Rheumatology, Freiburg, Germany; ${ }^{11}$ University of Florence, Rheumatolgy, Florence, Italy; ${ }^{12}$ University of Cantabria, Rheumatology, Santander, Italy

Background: ASSD is characterized by antisynthetase antibodies (ARS) and the triad arthritis/myositis/Interstitial Lung Disease (ILD). ASSD and systemic sclerosis (SSc) may share features, like Raynaud's phenomenon (RP), capillaroscopic alterations, and also some SSc specific autoantibodies.

Objectives: To evaluate the characteristics of ASSD + for anticentromere antibodies (ACA).

Methods: Retrospective analysis of clinical and laboratory characteristics of ACA + ASSD. Patients were identified in an established international cohort, randomly matched 1:1 for sex, age, disease duration and ARS positivity with a group of ACA - ASSD.

Results: 18 ACA + ASSD (15 females, 83\%, 15 anti-Jo1, 2 anti-PL7, 1 anti-PL12 ARS) patients were identified. In comparison to ACA - group, no differences were observed in disease clinical presentation and evolution. Though, 9 ACA + patients (50\%) satisfied the ACR/EULAR 2013 classification criteria for SSc and only 1 in ACA - group ( $p=0.007)$ (Table 1$)$.

An incomplete ASSD (lack of at least one triad finding) was observed in 15 patients in both ACA + and - group $(p=1)$. Among these patients, $13 A C A+$ and 11 ACA - developed de-novo triad finding during disease course $(p=0.651)$. In $\mathrm{ACA}+$ group, a de-novo arthritis was observed in 4 patients (vs $1, \mathrm{p}=0.565$ ), a de-novo myositis in 8 (vs $5, p=1$ ), and a de-novo ILD in 7 (vs 10, $p=1$ ). The prevalence of complete forms was similar between ACA + and - group at both disease onset ( 3 vs $3,17 \%, p=1$ ) and last follow-up, (10 vs $11,56 \%$ vs $61 \%$, $p=1)$. Of note, only 1 patient $(6 \%)$ for each group died $(p=1)$.

Conclusion: The clinical spectrum time course of ACA+ and - ASSD is similar, even when ACA + patients could be classified as SSc. By considering the high prevalence of arthritis and myositis we observed, we suggest that ACA+ patients with arthritis and myositis, should be tested for ARS antibodies even when an ASSD is not clearly suspected.

References:

[1] Mirrakhimov AE. Curr Med Chem 2015;22:1963-75

[2] Cavagna L. J Clin Med 2019;8:E2013

[3] Sebastiani M. J Rheum 2019:46:279-84

[4] van den Hoogen F. Ann Rheum Dis 2013;72:1747-55

Table 1. Patients characteristics. IQR, interquartile range; ILD, interstitial Lung Disease; SSc, systemic sclerosis

\begin{tabular}{lccc}
\hline & ACA+ (18) & ACA - (18) & $\mathrm{p}$ \\
\hline Age (years) at disease onset (median, IQR) & $47(37-63)$ & $47(39-63)$ & 0.834 \\
Disease duration (months) (median, IQR) & $81(62-169)$ & $77(58-165)$ & 0.486 \\
anti Ro52 antibody (\%) & $12(67)$ & $11(61)$ & 1 \\
Arthritis onset & $10(56)$ & $13(72)$ & 0.489 \\
Arthritis last follow-up (\%) & $14(78)$ & $14(78 \%)$ & 1 \\
Myositis onset (\%) & $7(39)$ & $11(61)$ & 0.318 \\
Myositis last follow-up (\%) & $15(83)$ & $16(89)$ & 1 \\
ILD onset (\%) & $9(50)$ & $6(33)$ & 0.5 \\
ILD last follow-up (\%) & $16(89)$ & $16(89)$ & 1 \\
Complete form onset (\%) & $3(17)$ & $3(17)$ & 1 \\
Complete form last follow-up (\%) & $10(56)$ & $11(61)$ & 1 \\
Raynaud phenomenon (\%) & $13(72)$ & $9(50)$ & 0.305 \\
Mechanic's hands (\%) & $6(33)$ & $7(38)$ & 1 \\
Teleangectasias (\%) & $2(11)$ & $0(0)$ & 0.486 \\
Cutaneous sclerosis (\%) & 5 & 1 & 0.177 \\
Acral ulcers (\%) & $1(6)$ & $0(0)$ & 1 \\
Scleroderma pattern at NVC & $8(44)$ & $7(39)$ & 1 \\
Pulmonary arterial hypertension (\%) & $3(17)$ & $2(11)$ & 1 \\
2013 ACR/EULAR SSc classification criteria & $9(50)$ & $1(6)$ & 0.007 \\
\hline
\end{tabular}

Disclosure of Interests: Giovanni Zanframundo: None declared, Gianluca Sambataro: None declared, Veronica Codullo: None declared, Alessandro Biglia: None declared, Emanuele Bozzalla Cassione: None declared, Elena Bravi: None declared, Florenzo lannone Consultant of: Speaker and consulting fees from AbbVie, Eli Lilly, Novartis, Pfizer, Roche, Sanofi, UCB, MSD, Speakers bureau: Speaker and consulting fees from AbbVie, Eli Lilly, Novartis, Pfizer, Roche, Sanofi, UCB, MSD, Marco Fornaro: None declared, Konstantinos Triantafyllias: None declared, Alberto Pesci: None declared, Paola Tomietto: None declared, Øyvind Molberg: None declared, Salvatore Scarpato: None declared, Reinhard Voll: None declared, Marco Matucci-Cerinic Grant/research support from: Actelion, MSD, Bristol-Myers Squibb, Speakers bureau: Acetelion, Lilly, Boehringe Ingelheim, Miguel A González-Gay Grant/research support from: Pfizer, Abbvie, MSD, Speakers bureau: Pfizer, Abbvie, MSD, Carlomaurizio Montecucco: None declared, Lorenzo Cavagna: None declared

DOI: 10.1136/annrheumdis-2020-eular.3760

\section{SATURDAY, 06 JUNE 2020}

\section{Spondyloarthritis - etiology, pathogenesis and animal models}

\section{SAT0349 CTLA4-IG DECREASES TH17 CELL LEVELS BUT MAINTAINS ILC3S WITH AN INCREASE IN THE ILC3/ ILC1 RATIO IN THE GUT OF SKG MICE AS A MODEL OF SPONDYLOARTHRITIS.}

Y. Tabuchi ${ }^{1}$, M. Hashimoto ${ }^{2}$, S. Akizuki ${ }^{1}$, R. Nakashima ${ }^{1}$, K. Murakami ${ }^{1}$, H. Yoshifuji ${ }^{1}$, M. Tanaka ${ }^{2}$, K. Ohmura ${ }^{1} .{ }^{1}$ Graduate Shool of Medicine, Kyoto University, Department of Rheumatology and Clinical Immunology, Kyoto, Japan; ${ }^{2}$ Graduate School of Medicine, Kyoto University, Department of Advanced Medicine for Rheumatic Diseases, Kyoto, Japan

Background: SKG mice have been known for their autoreactive Th17 cells resulting from the insufficient thymic negative selection due to a Zap70 mutation ${ }^{1,2)}$. Under specific pathogen-free conditions, they acquire features of spondyloarthritis (SpA) by intraperitoneal injection of curdlan, a $(1,3)-\beta$-glucan ${ }^{3}$. Several reports have shown that Th17 cells also increase in human $\mathrm{SpA}^{4)}$. However, CTLA4-lg, which ameliorates rheumatoid arthritis by suppressing pathogenic cells such as effector $T$ cells, was unable to show adequate efficacy as much as expected in SpA patients ${ }^{5}$. Around the same time, innate lymphocytes began to be focused on, in the pathogenesis of SpA, including innate lymphoid cells (ILCs), which abundantly reside in the gut ${ }^{6}$. Objectives: This study aimed to clarify the effects of CTLA4-Ig on the pathogenesis of SpA by using curdlan-treated SKG mice, focusing on type 3 immunity such as Th17 cells and ILC3s.

Methods: Two- to three-month-old female SKG mice were injected intraperitoneally with $3 \mathrm{mg}$ of curdlan or PBS at the beginning and with $500 \mu \mathrm{g}$ of CTLA4-Ig or PBS every other week ( $n=5$ per group). The body weight and arthritis score were measured weekly for a month. Then, the changes in the proportion of $\mathrm{T}$ cells and ILCs in the spleen and Peyer's patches (PPs) were analysed by flow cytometry (FCM). BALB/c mice, without treatment, were also examined by FCM as a contro cohort. In addition, a next-generation analysis of their feces was performed on 16S ribosomal coding genes before curdlan and CTLA4-Ig treatment.

Results: SKG mice contained not only more Th17 cells but also more ILC1s and ILC3s than BALB/c mice, in their guts (the PPs). The feces of SKG mice intrinsically showed a decrease in the number of bacterial species, suggesting a dysbiosis. Then, in curdlan-treated SKG mice, CTLA4-Ig administration decreased the proportion of both Th17 cells and ILC3s in the spleen, but did not decrease the proportion of ILC3s in the PPS. Moreover, the ILC3/ILC1 ratio in the PPs was from low to high in the order of SKG mice without treatment, SKG mice injected with curdlan, and SKG mice injected with both curdlan and CTLA4-lg. The phenotype corresponding to SpA features, in curdlan-treated SKG mice, continued after repeated CTLA4-Ig administration.

Conclusion: Curdlan provoked SpA features in SKG mice with an intrinsic dysbiosis. Additional CTLA4-Ig injection decreased the proportion of Th17 cells but maintained that of ILC3s with increased ILC3/ILC1 ratio in the gut. This result supports the hypothesis that in the SpA pathophysiology, a weakened acquired immunity in the gut might lead to ILC3 activation, via dysbiosis, and its continuous disease progression, suggesting that ILC3s are a promising therapeutic target in $\mathrm{SpA}$

References:

[1] Sakaguchi N, Sakaguchi S, et al. Altered thymic T-cell selection due to a mutation of the ZAP-70 gene causes autoimmune arthritis in mice. Nature 2003;426:454-460

[2] Hirota K, Sakaguchi S, et al. T cell self-reactivity forms a cytokine milieu for spontaneous development of IL-17+ Th cells that cause autoimmune arthritis. J Exp Med 2007;204:41-47. 
[3] Ruutu M, Thomas R, et al. $\beta$-glucan triggers spondylarthritis and Crohn's disease-like ileitis in SKG mice. Arthritis Rheum 2012;64:2211-2222.

[4] Shen H, Gaston JS, et al. Frequency and phenotype of peripheral blood Th17 cells in ankylosing spondylitis and rheumatoid arthritis. Arthritis Rheum 2009;60:1647-1656.

[5] Song I-H, Sieper J, et al. Treatment of active ankylosing spondylitis with abatacept: an open-label, 24-week pilot study. Ann Rheum Dis 2011;70:1108-1110.

[6] Ciccia F, Triolo $G$, et al. Type 3 innate lymphoid cells producing IL-17 and IL-22 are expanded in the gut, in the peripheral blood, synovial fluid and bone marrow of patients with ankylosing spondylitis. Ann Rheum Dis 2015; $74: 1739-1747$

\section{ILCs in PPs}

$(\%$ in the jejunum

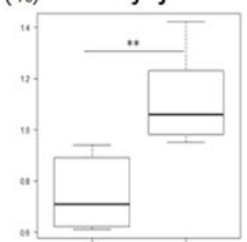

$B A L B / c \quad$ SKG

$$
\text { ILCs in PPS }
$$

in the ileum

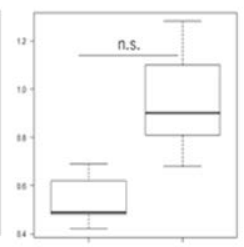

$B A L B / c \quad$ SKG

\section{ILCs in PPs in the whole small intestine}

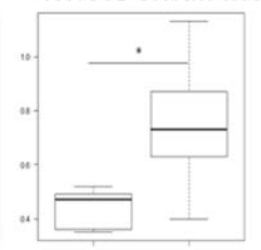

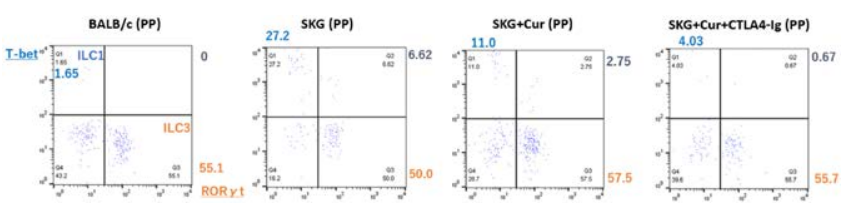

Disclosure of Interests: Yuya TABUCHI Paid instructor for: Astellas Pharma, GlaxoSmithKline, Mitsubishi Tanabe Pharma, and Nippon Shinyaku., Speakers bureau: AbbVie, Janssen Pharmaceutical, Mitsubishi Tanabe Pharma, Nippon Shinyaku, and Novartis Pharma., Motomu Hashimoto Grant/research support from: Bristol-Myers Squibb, Eisai, and Eli Lilly and Company., Speakers bureau: Bristol-Myers Squibb and Mitsubishi Tanabe Pharma., Syuji Akizuki: None declared, Ran Nakashima Grant/research support from: Takeda Pharmaceutical. (Outside the field of the present study.), Speakers bureau: Astellas Pharma, Medical \& Biological Laboratories, AstraZeneca, and Boehringer Ingelheim. (Outside the field of the present study.), Kosaku Murakami Speakers bureau: AbbVie, Eisai, and Mitsubishi Tanabe Pharma., Hajime Yoshifuji Grant/research support from: Astellas Pharma. (Outside the field of the present study.), Speakers bureau: Chugai Pharmaceutical. (Outside the field of the present study.), Masao Tanaka Grant/research support from: AbbVie, Asahi Kasei Pharma, Astellas Pharma, Ayumi Pharmaceutical, Chugai Pharmaceutical, Eisai, Mitsubishi Tanabe Pharma, Taisho Pharmaceutical, and UCB Japan.

, Speakers bureau: AbbVie, Asahi Kasei Pharma, Astellas Pharma, Bristol-Myers Squibb, Chugai Pharmaceutical, Eisai, Eli Lilly and Company, Janssen Pharmaceutical, Mitsubishi Tanabe Pharma, Novartis Pharma, Pfizer, Taisho Pharmaceutical, Takeda Pharmaceutical, and UCB Japan., Koichiro Ohmura Grant/research support from: Astellas Pharma, AYUMI Pharmaceutical, Chugai Pharmaceutical, Daiichi Sankyo, Eisai, Japan Blood Products Organization, Mitsubishi Tanabe Pharma, Nippon Kayaku, Nippon Shinyaku, Sanofi, and Takeda Pharmaceutical., Speakers bureau: AbbVie, Actelion Pharmaceuticals Japan, Asahi Kasei Pharma, AYUMI Pharmaceutical, Bristol-Myers Squibb, Chugai Pharmaceutical, Eisai, Eli Lilly and Company, GlaxoSmithKline, Janssen Pharmaceutical, Mitsubishi Tanabe Pharma, Novartis Pharma, and Sanofi.

DOI: 10.1136/annrheumdis-2020-eular.1117

\section{SAT0350 \\ A ROLE FOR IL-17A IN THE SUPPRESSION OF SPINAL ENTHESEAL MESENCHYMAL STEM CELL ADIPOGENESIS WHILST SIMULTANEOUSLY FACILITATING OSTEOGENESIS.}

T. Russell ${ }^{1}$, C. Bridgewood ${ }^{1}$, A. Khan ${ }^{2}$, A. S. Rao' ${ }^{2}$, P. Loughenbury ${ }^{2}$, P. Millner², R. Dunsmuir ${ }^{2}$, A. Altaie ${ }^{1}$, E. Jones ${ }^{1}$, D. Mcgonagle ${ }^{1} .{ }^{1}$ University of Leeds, Leeds Institute of Rheumatic and Musculoskeletal Medicine, Leeds, United Kingdom; ${ }^{2}$ Leeds Teaching Hospitals NHS Trust, Leeds, United Kingdom

Background: Fat formation in the bone adjacent to the enthesis is an important but poorly characterised intermediate stage in new bone formation that occurs in the spine in AS. We and others have previously reported that IL-17A can increase mesenchymal stem cell (MSC) mediated osteogenesis in normal and AS spinal tissue $(1,2)$.

Objectives: Herein we investigate the impact of IL-17A \& TNF on MSC adipogenesis from spinal enthesis tissue.

Methods: Samples from healthy spinous process and interspinous ligament $(n=14$, median age $=53$ ) were separated into the peri-entheseal bone (PEB) and entheseal soft tissue (EST) \& enzymatically digested. Minimally passaged $(<p 3)$ MSCs were cultured in a complete adipogenic media, with some cultures supplemented with either IL-17A $(50 \mathrm{ng} / \mathrm{ml})$, TNF $(1 \mathrm{ng} / \mathrm{ml})$ or IL-17A \& TNF for 3 weeks. Adipogeneis was quantitatively assessed by Oil Red $\mathrm{O}$ staining at day 21. IL-17A's effect on adipogeneis was further investigated by RNA extractions at Day $0,3,5,7,15 \& 21$ with supporting Oil Red O staining. 48 adipogenic and IL-17A target genes were used to investigate adipogenic progression and IL-17A effects on it over 21 day adipogenic differentiation.

Results: EST MSCs have a significantly higher adipogenic potential than matched PEB MSCs $(n=14, p<0.001)$. TNF and IL-17A both cause significant decreases (all $p<0.01, n=5$ ) in adipogenesis for both PEB and EST MSCs. EST MSCs produced lipid vesicles by day-3 post-induction, with significant inhibition by IL-17A $(p<0.01, n=4)$ seen from day 15 onwards. IL-17A caused a significant decrease in overall Oil Red $\mathrm{O}$ staining, and it changed the morphology of lipid vesicles with a majority of cells consistent with immature pre-adipocytes. This was supported by gene expression data, which indicated significant decreases in transcripts encoding vesicle fusion proteins (CIDEC $p<0.05$, PLIN1 $p<0.01$ ). PLIN1 also aids protection against lipolysis (4). Transcripts associated with osteogenesis (CEBP $\beta$ (3)) and MSC stromal support (CXCL12) were significantly upregulated in adipogenically-induced cultures stimulated with IL-17A when compared to control adipogenic media. TNF \& IL-17A combination demonstrated that IL-17A drove the vesicle morphology changes, with TNF alone not showing the same vesicle changes.

Conclusion: Given the inverse link between MSC mediated osteogeneis \& adipogenesis, these findings reveal a role of IL-17A especially on EST MSCs. The rapid formation of adipocytes seen in EST MSCs may be relevant to MRI determined peri-entheseal bone "shiny corners" due to post inflammation fat accumulation. Elevated transcripts associated with pre-adipocytes \& undifferentiated MSCs support the idea of plasticity between early osteogenesis \& adipogenesis. Downregulation of transcripts for proteins associated with protection against lipolysis allows for the rationalising of the gradual loss of the shiny corners seen in AS preceding subsequent new bone formation.

References:

[1] RUSSELL, T., A. WATAD, C. BRIDGEWOOD, A. KHAN, A.S. RAO, P. LOUGHENBURY, P. MILNER, R. DUNSMUIR, T. BABOOLAL, E. JONES, R. CUTHBERT and D. MCGONAGLE. IL-17A Induces Distinct Functional Differences Between Two Novel Mesenchymal Stem Cell Populations Identified at the Human Enthesis. Arthritis Rheumatol, 2019, 71 Suppl 10, pp.1-5362.

[2] JO, S., S.E. WANG, Y.L. LEE, S. KANG, B. LEE, J. HAN, I.H. SUNG, Y.S. PARK, S.C. BAE and T.H. KIM. IL-17A induces osteoblast differentiation by activating JAK2/STAT3 in ankylosing spondylitis. Arthritis Res Ther, 2018, 20(1), p.115.

[3] AHMED, M. and S.L. GAFFEN. IL-17 in obesity and adipogenesis. Cytokine Growth Factor Rev, 2010, 21(6), pp.449-53.

[4] HANSEN, J.S., S. DE MARE, H.A. JONES, O. GORANSSON and K. LINDKVIST-PETERSSON. Visualization of lipid directed dynamics of perilipin 1 in human primary adipocytes. Sci Rep, 2017, 7(1), p.15011.

Disclosure of Interests: Tobias Russell Grant/research support from: Novartis UK Investigator Initiated non-clinical research funding support, Charlie Bridgewood: None declared, Almas Khan: None declared, Abhay S Rao: None declared, Peter Loughenbury: None declared, Peter Millner: None declared, Robert Dunsmuir: None declared, Ala Altaie: None declared, Elena Jones: None declared, Dennis McGonagle Grant/research support from: Janssen Research \& Development, LLC DOI: 10.1136/annrheumdis-2020-eular.2820

\section{SAT0351 CHEMOKINE PATHWAYS ARE ENRICHED IN PSORIATIC ARTHRITIS (PSA) SKIN LESIONS WITH INCREASED EXPRESSION OF ATYPICAL CHEMOKINE RECEPTOR 2 (ACKR2)}

H. Johnsson ${ }^{1}$, J. Cole ${ }^{1}$, G. Wilson ${ }^{1}$, M. Pingen ${ }^{1}$, F. Mcmonagle ${ }^{1}$, S. Holmes ${ }^{2}$, I. Mcinnes ${ }^{1}$, S. Siebert ${ }^{1}$, G. Graham ${ }^{1}$. ${ }^{1}$ University of Glasgow, Institute of Infection, Immunity and Inflammation, Glasgow, United Kingdom; ${ }^{2}$ Alan Lyell Centre for Dermatology, Glasgow, United Kingdom

Background: Skin in people with psoriasis has been comprehensively studied; uninvolved skin has abnormal gene expression. Less is known specifically about skin in PsA, the assumption being that it is identical to psoriasis. Chemokines and ACKR2 are among the upregulated genes in uninvolved psoriasis compared 